Supporting information

\title{
Rapid Defrost Transparent Thin Film Heater with Flexibility and Chemical Stability
}

Joohee Jang,,$\ldots$ Narendra S. Parmar, ${ }^{\dagger}$ Won-Kook Choi, $\$$ and Ji-Won Choi,,,,$+ *$

${ }^{\dagger}$ Center for Electronic Materials, Korea Institute of Science and Technology (KIST), 5, Hwarang-ro 14 gil, Seongbuk-gu, Seoul, 02792, Republic of Korea

\$ Division of Nano \& Information Technology, KIST school, University of Science and Technology (UST), 217, Gajeong-ro, Yuseong-gu, Daejeon, 34113, Republic of Korea

$\S$ Center for Opto-Electronic Materials and Devices, Korea Institute of Science and Technology (KIST), 5, Hwarang-ro 14-gil, Seongbuk-gu, Seoul, 02792, Republic of Korea

\#These authors contributed equally to this work.

*Corresponding author: Ji-Won Choi at jwchoi@kist.re.kr 


\section{The ZTO thin films deposited on glass substrates by $\mathbf{O}_{2}$-to-Ar gas ratio}

Figure S1 shows the effect of the gas combination on the electrical and optical properties of the ZTO thin films deposited at room temperature on glass substrates as the $\mathrm{O}_{2}$-to-Ar gas ratio was varied. The thickness of the ZTO thin films was $150 \mathrm{~nm}$, which was measured by SEM (Figure $\mathrm{S} 1 \mathrm{a})$. The sheet resistance increased from $0.32 \mathrm{k} \Omega ~ s q^{-1}$ to $524 \mathrm{k} \Omega ~ s q^{-1}$ (Figure $\mathrm{S} 1 \mathrm{~b}$ ) as the $\mathrm{O}_{2}$-toAr gas ratio was changed from 0 to $1.5 \%$. The transmittance in the $550 \mathrm{~nm}$ wavelength region was varied from $78.4 \%$ to $85.1 \%$ when the $\mathrm{O}_{2}$-to-Ar gas ratio changed from $0-1.5 \%$ (Figure $\mathrm{S} 1 \mathrm{c}$ ). The ZTO thin film showed the lowest electrical resistance $\left(0.32 \mathrm{k} \Omega \mathrm{sq}^{-1}\right)$ and the highest optical transmittance $(85.1 \%)$ at an oxygen concentration of $0.3 \%$, as compared to the other oxygen concentrations during the growth. Figure S1d shows the Hall measurement data of the ZTO thin film as a function of the oxygen concentration $(0 \%, 0.2 \%, 0.3 \%, 0.4 \%, 0.5 \%, 0.75 \%, 1.0 \%, 1.5 \%)$. All ZTO thin films have $n$-type conduction. When the oxygen concentration changed from $0 \%$ to $0.3 \%$, the resistivity decreased slightly from $7.21 \times 10^{-3}$ to $4.90 \times 10^{-3} \Omega \mathrm{cm}$. Thereafter, as the oxygen concentration increased to $1.5 \%$, the resistivity increased to $7.86 \times 10^{-3} \Omega \mathrm{cm}$. The lowest resistivity $\left(4.90 \times 10^{-3} \Omega \mathrm{cm}\right)$ was observed at the $0.3 \%$ oxygen concentration. Moreover, as the oxygen concentration increased from $0-0.3 \%$, the carrier concentration increased and reached a maximum value $\left(6.97 \times 10^{19} \mathrm{~cm}^{-3}\right)$ at the $0.3 \%$ oxygen concentration. Consequently, the carrier concentration continuously decreased and dropped to $1.06 \times 10^{17} \mathrm{~cm}^{-3}$ at the $1.5 \%$ oxygen concentration. The Hall mobility of the ZTO thin film varied in the range $7.2-23.45 \mathrm{~cm}^{2} \mathrm{~V}^{-1} \mathrm{~s}^{-1}$ depending on the oxygen concentration (0-1.5\%) during the growth. The mobility reached its maximum value $\left(23.45 \mathrm{~cm}^{2} \mathrm{~V}^{-1} \mathrm{~s}^{-1}\right)$ at an oxygen concentration of $0.4 \%$. Based on the results of carrier concentration and mobility, when the oxygen concentration of $0.3 \%$ was incorporated during the growth, the resistivity decreased significantly because of the increase in the carrier 
concentration and Hall mobility. Figure S2 shows the high-resolution core level XPS spectra of the ZTO thin films as a function of the oxygen concentration $(0 \%, 0.3 \%, 1.0 \%)$. Figure S2a shows $\mathrm{Sn}(3 \mathrm{~d})$ core level spectra that is deconvoluted into two Gaussian components at $486.0 \mathrm{eV}$ and $486.7 \mathrm{eV}$, corresponding to the $\mathrm{Sn}(+2, \mathrm{SnO})$ state and the $\mathrm{Sn}\left(+4, \mathrm{SnO}_{2}\right)$ state, respectively ${ }^{1,2}$. It can be seen that the binding energy peak moved towards $\mathrm{SnO}_{2}$ at an oxygen concentration of $0.3 \%$ as compared to the other growth conditions where it shifted towards SnO. The dependence of the electrical properties on the oxygen partial pressure is understood to be because of the number of vacancies and excess metal ions arising from the non-stoichiometry change in an oxygen environment. A trade-off between the $\mathrm{SnO}$ and $\mathrm{SnO}_{2}$ phases gives rise to a relatively high carrier density at the oxygen concentration of $0.3 \%$ (Figure S1d). As the oxygen concentration increased to $0.3 \%$, the mobility increased due to the decrease in the amount of the $\mathrm{SnO}$ phase. As a result, the resistivity decreased with increasing oxygen concentration, as can be seen in Figure S1d. In a more oxidizing atmosphere, a decrease in the number of oxygen vacancies and excess metal ions takes place ${ }^{3}$. Therefore, films exhibit lower carrier concentrations and a higher resistivity at higher oxygen concentrations. Figure S2b shows the $\mathrm{O}$ 1s transition peaks as a function of the oxygen concentration $(0 \%, 0.3 \%$, and $1.0 \%)$. We can see that as the oxygen content increased from $0 \%$ to $1.0 \%$ during deposition, the peak shifted towards the higher binding energy. This is because of the higher binding energy of $\mathrm{ZnO}(530.7 \mathrm{eV})^{4}$ as compared to $\mathrm{SnO}_{2}(530.1 \mathrm{eV})^{5}$. It is evidence of $\mathrm{Zn}$ doping as the Zn-O bond increases. Figure S2c shows $2 p$ orbitals split (of $Z n 2 p$ ) into the $2 p_{3 / 2}$ and $2 \mathrm{p}_{1 / 2}$ doublet peaks. As the concentration of oxygen increased from $0 \%$ to $1.0 \%$ during deposition, the intensity of the $\mathrm{Zn} 2 \mathrm{p}$ peak increased, indicating that more $\mathrm{Zn}-\mathrm{O}$ bonds were formed in the thin films. According to previous studies, the chemical shifts between Sn metal and its stoichiometric $\mathrm{SnO}_{2}$ powder observed as much as $6 \pm 1 \mathrm{eV}$ in Auger electron spectroscopy (AES) and $2.39 \pm 0.02$ 
$\mathrm{eV}$ in X-ray photoelectron spectroscopy (XPS) ${ }^{6}$. These large discrepancies in chemical shifts between AES and XPS result from differences in the electronic polarization energy of the final two-hole state in Auger electron emission and the final single-hole state produced in photoelectron emission. This result shows the AES is more efficient in determining the relative oxygen-to-Sn ratio in nonstoichiometric $\mathrm{SnO}_{\mathrm{x}}$ thin films. By means of comparison, as shown in Figure $\mathrm{S} 3$, the AES spectra for all the ZTO films and the standard $\mathrm{SnO}_{2}$ powder, as a reference, were taken together. The position of the $\operatorname{Sn} N_{4} M_{4,5} M_{4,5}$ and the O KLL AES peak for all the films and the standard $\mathrm{SnO}_{2}$ powder were not clearly distinguished and found at almost the same energy levels of $435 \mathrm{eV}$ and $513.7 \mathrm{eV}$, respectively. The atomic ratio $\left(\mathrm{N}_{\mathrm{o}} / \mathrm{N}_{\mathrm{Sn}}\right)$ of the fabricated $\mathrm{SnO}_{\mathrm{x}}$ films were confirmed from the ratio of the peak-to-peak heights of $\operatorname{Sn} N_{4} M_{4,5} M_{4,5}$ and $\mathrm{O} K L_{2,3} L_{2,3}$ in the Auger spectra and adjusted by means of a correction factor. If the valence of stoichiometric $\mathrm{SnO}_{2}$ powder $\left(\mathrm{N}_{\mathrm{o}} / \mathrm{N}_{\mathrm{Sn}}=2\right)$ is assumed to be +4 , the virtual valence $(\sigma)$ of the ZTO films can be deduced to be $\sigma=1.65,1.66$, and 1.86 , respectively. It increased slightly due to the increment of partial oxygen content in the plasma gas environment. 


\section{REFERENCES}

(1) Moulder, J. F.; Stickle, W. F.; Sobol, P. E.; Bomben, K. D. Handbook of X-Ray

Photoelectron Spectroscopy; Chastain, J., Ed.; Perkin-Elmer Corporation: Waltham, 1992.

(2) Wohlmuth, W.; Adesida, I. Properties of R.F. Magnetron Sputtered Cadmium-Tin-Oxide and Indium-Tin-Oxide Thin Films. Thin Solid Films 2005, 479, 223-231.

(3) Hao, X.; Ma, J.; Zhang, D.; Yang, Y.; Xu, X.; Chen, F.; Ma, H. Electrical and Optical Properties of SnO2:Sb Films Prepared on Polyimide Substrate by r.f. Bias Sputtering. Appl. Surf. Sci. 2002, 189 (1-2), 157-161.

(4) Deroubaix, G.; Marcus, P. X-ray Photoelectron Spectroscopy Analysis of Copper and Zinc Oxides and Sulphides. Surf. Inter. Anal. 1992, 18 (1), 39-46.

(5) Shuttleworth, D. Preparation of Metal-Polymer Dispersions by Plasma Techniques. An ESCA Investigation. J. Phys. Chem. 1980, 84 (12), 1629-1634.

(6) Choi, W.-K.; Cho, J.-S.; Song, S.-K.; Jung, H.-J.; Koh, S.-K. Auger Electron and X-Ray Photoelectron Spectroscopy Studies of Oxidation of Tin Using SnOx Thin Films Grown by Reactive Ion-Assisted Deposition. Jpn. J. Appl. Phys. 1996, 35 (11), 5820-5824.

(7) Yu, S. H.; Jia, C. H.; Zheng, H. W.; Ding, L. H.; Zhang, W. F. High Quality Transparent Conductive $\mathrm{SnO}_{2} / \mathrm{Ag} / \mathrm{SnO}_{2}$ tri-Layer Films Deposited at Room Temperature by Magnetron Sputtering. Mater. Lett. 2012, 85, 68-70. 
(8) Yu, S.; Zhang, W.; Li, L.; Xu, D.; Dong, H.; Jin, Y. Optimization of $\mathrm{SnO}_{2} / \mathrm{Ag} / \mathrm{SnO}_{2}$ triLayer Films as Transparent Composite Electrode with High Figure of Merit. Thin Solid Films 2014, 552, 150-154.

(9) Han, H.; Theodore, N. D.; Alford, T. L. Improved Conductivity and Mechanism of Carrier Transport in Zinc Oxide with Embedded Silver Layer. J. Appl. Phys. 2008, 103 (1) 013708-1-013708-8

(10) Lee, H. J.; Kang, J. W.; Hong, S. H.; Song, S. H.; Park, S. J. Mg $\mathrm{Zg}_{1-\mathrm{X}} \mathrm{O} / \mathrm{Ag} / \mathrm{Mg}_{\mathrm{x}} \mathrm{Zn}_{1-\mathrm{x}} \mathrm{O}$ Multilayers as High-Performance Transparent Conductive Electrodes. ACS Appl. Mater. Interfaces. 2016, 8 (3), 1565-1570.

(11) Roul, M. K.; Pradhan, S. K.; Song, K. D.; Bahoura, M. J. RF Magnetron-Sputtered Al$\mathrm{ZnO} / \mathrm{Ag} / \mathrm{Al}-\mathrm{ZnO}$ (AAA) Multilayer Electrode for Transparent and Flexible Thin-Film Heater. J. Mater. Sci. 2019, 54 (9), 7062-7071.

(12) Cho, Y.; Parmar, N. S.; Nahm, S.; Choi, J. W. Full Range Optical and Electrical Properties of $\mathrm{Zn}$-Doped $\mathrm{SnO}_{2}$ and Oxide/Metal/Oxide Multilayer Thin Films Deposited on Flexible PET Substrate. J Alloy Compd. 2017, 694, 217-222.

(13) Ji, S.; He, W.; Wang, K.; Ran, Y.; Ye, C. Thermal Response of Transparent Silver Nanowire/PEDOT:PSS Film Heaters. Small 2014, 10 (23), 4951-4960.

(14) Huang, Q.; Shen, W.; Fang, X.; Chen, G.; Guo, J.; Xu, W.; Tan, R.; Song, W. Highly Flexible and Transparent Film Heaters Based on Polyimide Films Embedded with Silver Nanowires. RSC Adv. 2015, 5 (57), 45836-45842. 
(15) Kiruthika, S.; Gupta, R.; Kulkarni, G. U. Large Area Defrosting Windows Based on Electrothermal Heating of Highly Conducting and Transmitting Ag Wire Mesh. RSC Adv. 2014, 4 (91), 49745-49751.

(16) Yoshikawa, R.; Tenjimbayashi, M.; Matsubayashi, T.; Manabe, K.; Magagnin, L.;

Monnai, Y.; Shiratori, S. Designing a Flexible and Transparent Ultrarapid

Electrothermogenic Film Based on Thermal Loss Suppression Effect: A Self-Fused Cu/Ni

Composite Junctionless Nanonetwork for Effective Deicing Heater. ACS Appl. Nano

Mater. 2018, 1 (2), 860-868. 
(a)

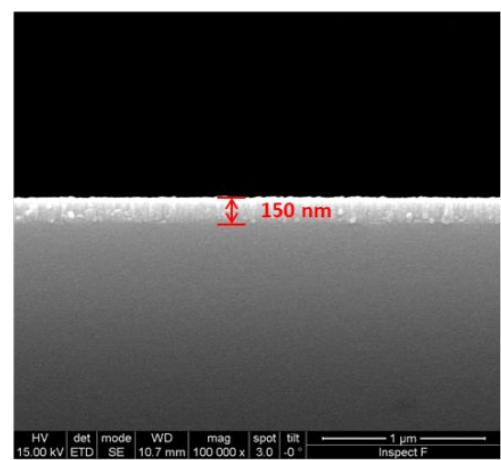

(c)

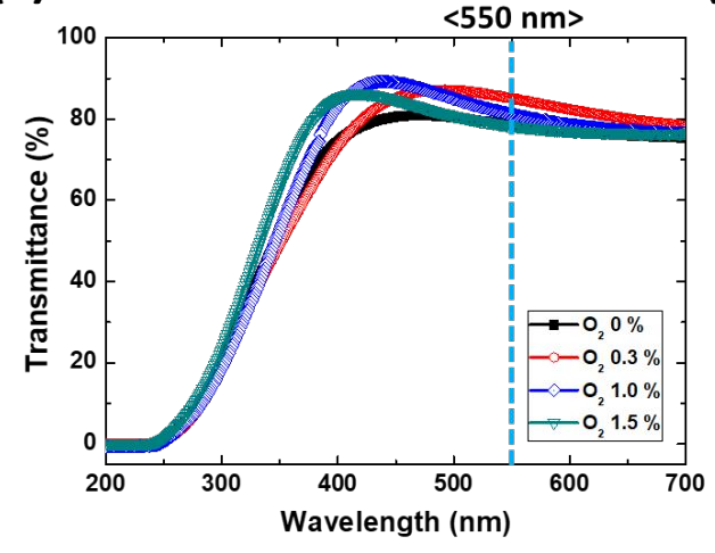

(b)

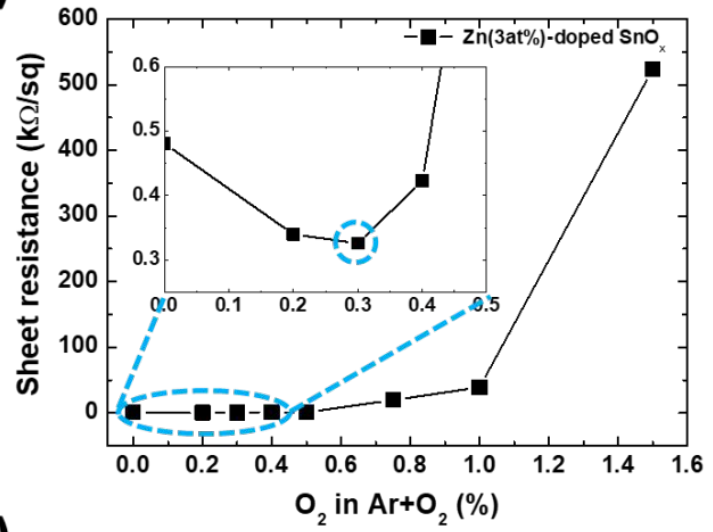

(d)

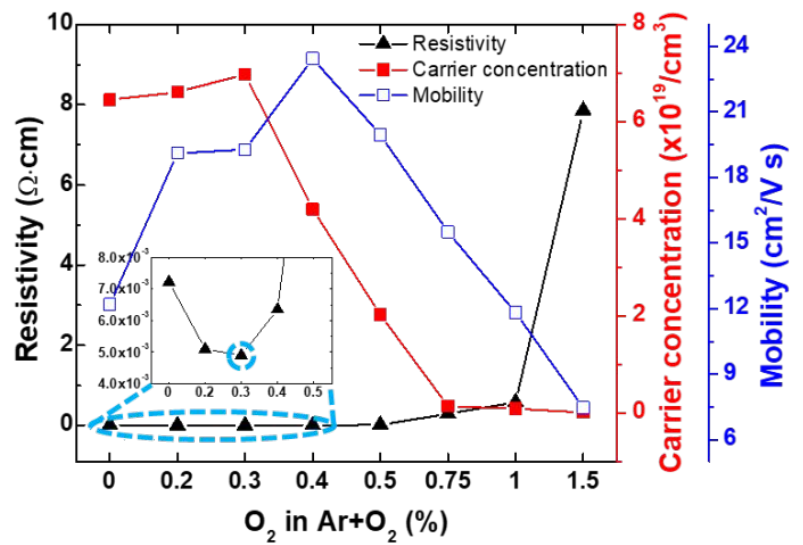

Figure S1. (a) SEM cross-section images of $\mathrm{Zn}$-doped $\mathrm{SnO}_{\mathrm{x}}$ thin film, (b) Sheet resistance, (b) Transmittance, and (c) Hall measurements data of the $\mathrm{Zn}$-doped $\mathrm{SnO}_{\mathrm{x}}$ thin films as $\mathrm{O}_{2}$-to-Ar gas ratio is varied. 

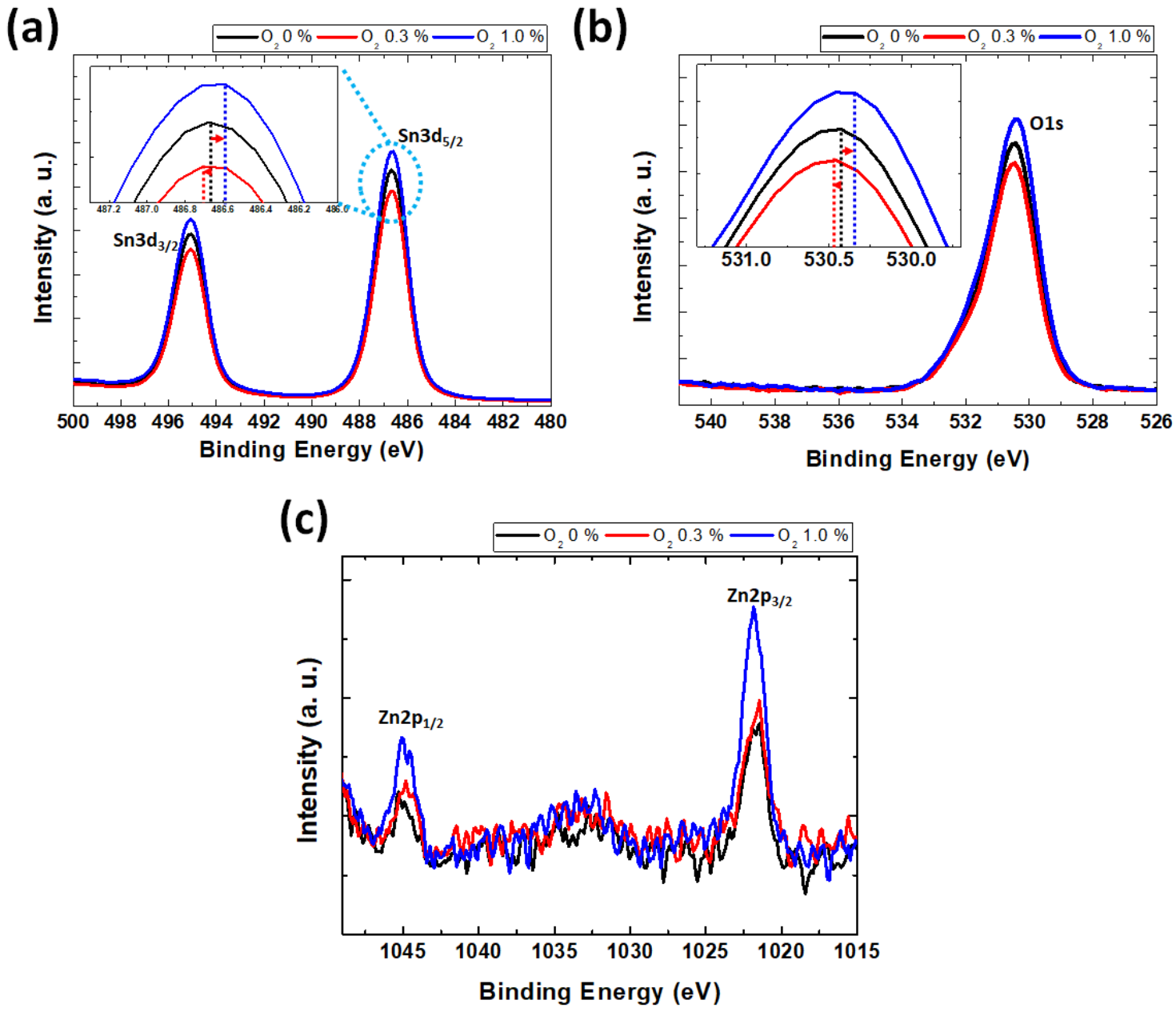

Figure S2. XPS spectra of the Zn-doped $\mathrm{SnO}_{\mathrm{x}}$ thin films, (a) Sn 3d, (b) O 1s, (c) Zn 2p. 


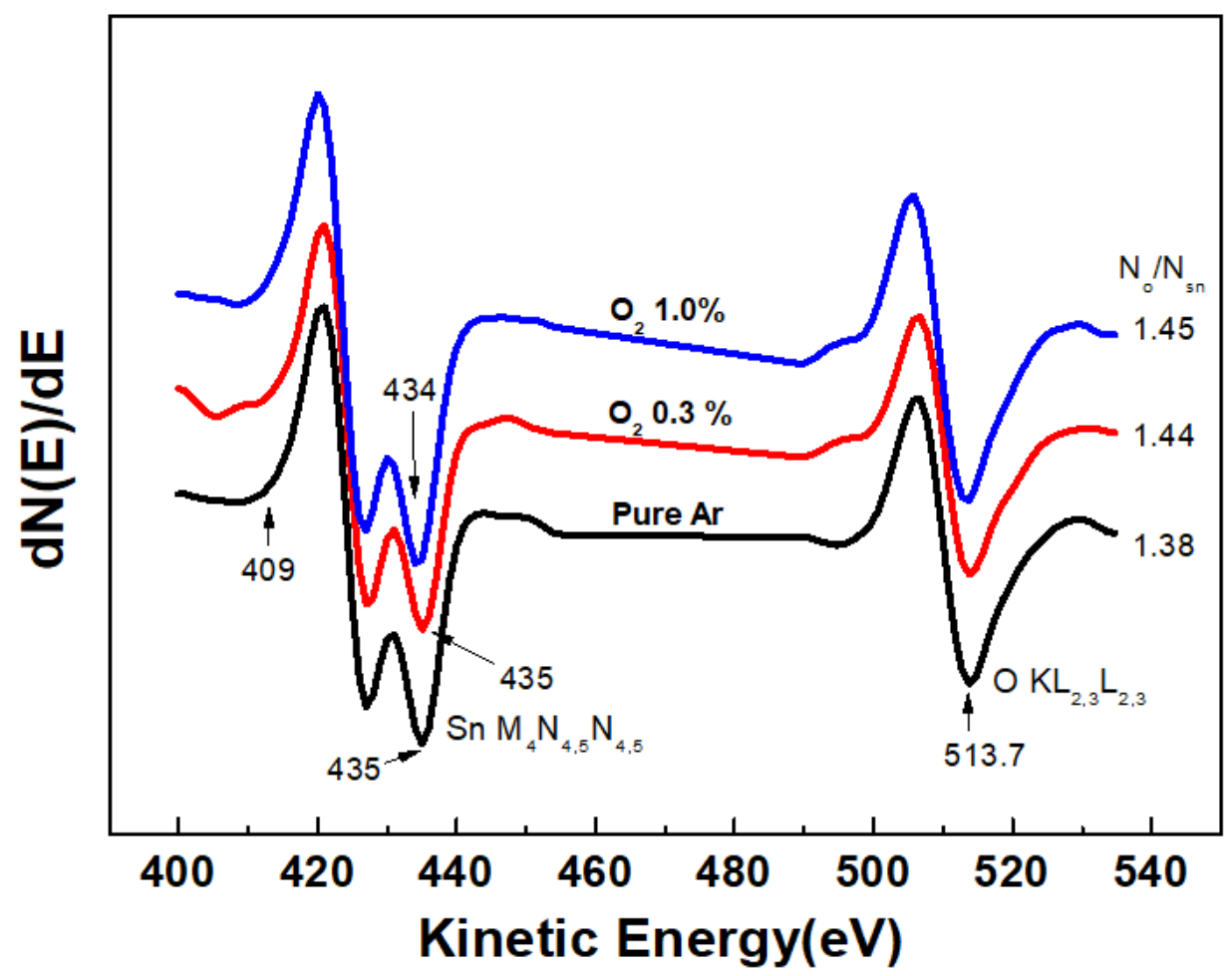

Figure S3. AES spectra of ( $\mathrm{Sn}$ metal,) $\mathrm{Zn}$-doped $\mathrm{SnO}_{\mathrm{x}}$ thin films deposited at pure $\mathrm{Ar}, 0.3 \%$ and $1.0 \% \mathrm{O}_{2}$ in $\mathrm{Ar}+\mathrm{O}_{2}$ atmosphere, and $\mathrm{SnO}_{2}$ powder, respectively. AES for $\mathrm{Zn}$-doped $\mathrm{SnO}_{\mathrm{x}}$ thin films were taken after depth profile of $90 \mathrm{~nm}$ with sputtering by $\mathrm{Ar}^{+}$ion. 
Table S1. Optical transmittance and sheet resistance value reported for several oxide/Ag/oxide, some of which have been deposited by magnetron sputtering

\begin{tabular}{|c|c|c|c|c|}
\hline OMO description & $\begin{array}{l}\text { Transmittance } \\
(\%, \text { at } 550 \mathrm{~nm})\end{array}$ & $\begin{array}{l}\text { Sheet resistance } \\
(\Omega / \mathbf{s q})\end{array}$ & Substrate & Ref. \\
\hline $\begin{array}{c}\mathrm{SnO}_{2} / \mathrm{Ag} / \mathrm{SnO}_{2} \\
(25 \mathrm{~nm} / 5 \mathrm{~nm} / 25 \mathrm{~nm})\end{array}$ & 83 & 9.61 & Quartz & 7 \\
\hline $\begin{array}{c}\mathrm{SnO}_{2} / \mathrm{Ag} / \mathrm{SnO}_{2} \\
(50 \mathrm{~nm} / 5 \mathrm{~nm} / 50 \mathrm{~nm})\end{array}$ & 94 & 9.67 & Quartz & 8 \\
\hline $\begin{array}{c}\mathrm{ZnO} / \mathrm{Ag} / \mathrm{ZnO} \\
(35 \mathrm{~nm} / 14 \mathrm{~nm} / 35 \mathrm{~nm})\end{array}$ & 75 & 6 & PET & 9 \\
\hline $\begin{array}{c}\mathrm{Mg}_{0.28} \mathrm{Zn}_{0.72} \mathrm{O} / \mathrm{Ag} / \mathrm{Mg}_{0.28} \mathrm{Zn}_{0.72} \mathrm{O} \\
\quad(50 \mathrm{~nm} / 14 \mathrm{~nm} / 50 \mathrm{~nm})\end{array}$ & 94 & 6.36 & Glass & 10 \\
\hline $\begin{array}{c}\mathrm{AZO} / \mathrm{Ag} / \mathrm{AZO} \\
(40 \mathrm{~nm} / 10 \mathrm{~nm} / 40 \mathrm{~nm})\end{array}$ & 85 & 6 & PET & 11 \\
\hline $\begin{array}{c}\mathrm{ZTO} / \mathrm{Ag} / \mathrm{ZTO} \\
(30 \mathrm{~nm} / 12 \mathrm{~nm} / 30 \mathrm{~nm})\end{array}$ & 85 & 7.6 & PET & 12 \\
\hline This work & 86 & 5.6 & PET & \\
\hline
\end{tabular}




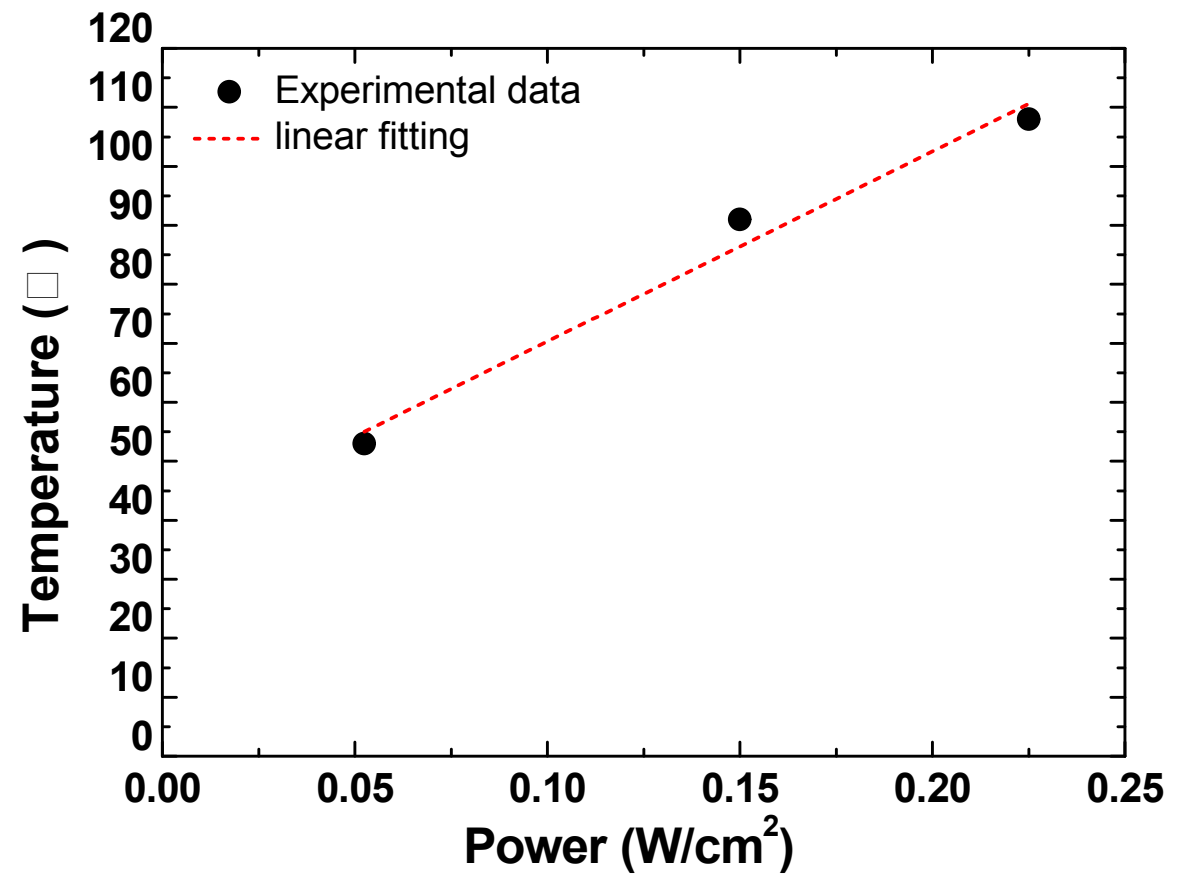

Figure S4. The temperature as a function of applied power for the ZTO/Ag/ZTO multilayer based thin film heater. 
Table S2. Optical transmittance and sheet resistance value reported for several oxide/Ag/oxide, some of which have been deposited by magnetron sputtering

\begin{tabular}{ccccc}
\hline Materials & $\begin{array}{c}\text { Power efficiency } \\
\left({ }^{\circ} \mathbf{C} \mathbf{~ c m}^{2} / \mathbf{W}\right)\end{array}$ & $\begin{array}{c}\text { Reliable heating- } \\
\text { cooling cycle }\end{array}$ & $\begin{array}{c}\text { Transmittance } \\
(\mathbf{\%}, \mathbf{a t} \text { 550 } \mathbf{~ m})\end{array}$ & Ref. \\
\hline ITO & 88 & - & - & 13 \\
\hline FTO & 119 & - & 58 & 14 \\
\hline Ag nanowire(AgNW) & 160 & 20 & 83 & 13 \\
\hline AgNW/PEDOT:PSS & 179 & 50 & 77 & 16 \\
\hline Ag wire mesh & 255 & 5 & 86 & This \\
\hline $\begin{array}{c}\text { Cu/Ni nano-network } \\
\text { ZTO/Ag/ZTO } \\
\text { multilayer }\end{array}$ & 421 & 20 & & work \\
\hline
\end{tabular}

